\title{
Impact of intraoperative medial collateral ligament injury on outcomes after total knee arthroplasty: a meta-analysis and systematic review
}

Jiahao Li ${ }^{1}$, Zijian Yan ${ }^{1}$, Yan Lv², Yijin Li ${ }^{1}$, Pengcheng Ye ${ }^{3}$, Peng Deng ${ }^{3}$, Haitao Zhang ${ }^{1}$, Jinlun Chen ${ }^{3}$, Jie Li ${ }^{3}$, Xinyu $\mathrm{Qi}^{3}$, Jianchun Zeng ${ }^{3}$, Yirong Zeng ${ }^{3^{*}}$ and Wenjun Feng ${ }^{3^{*}}$

\begin{abstract}
Background: As an uncommon but severe complication, medial collateral ligament (MCL) injury in total knee arthroplasty (TKA) may be significantly under-recognized. We aimed to determine whether MCL injury influences postoperative outcomes of patients undergoing TKA.

Methods: Two independent reviewers searched PubMed, Cochrane Library, and EMBASE from their inception to July 1, 2021. The main outcomes were postoperative function, and secondary outcomes included the incidences of revision and complications.

Results: A total of 403 articles yielded 15 studies eligible for inclusion with 10 studies used for meta-analysis. This study found that there was a statistically significant difference in postoperative functional scores, range of motion (ROM), complications, and revision rates, with adverse outcomes occurring more commonly in patients with $\mathrm{MCL}$ injury.
\end{abstract}

Conclusions: This meta-analysis highlights the complexity of MCL injury during TKA and shows the impact on postoperative function, joint mobility, complications, and revision. Surgeons need to prevent and put more emphasis on $M C L$ injury during TKA.

Keywords: Total knee arthroplasty, Medial collateral ligament, Meta-analysis

\section{Background}

As a well-established operation, total knee arthroplasty (TKA) was considered to be a highly effective method for the treatment of end-stage knee osteoarthritis [1]. Over the past decade, the number of total knee replacements performed annually has increased significantly. According to research, by 2030, the demand for primary total

\footnotetext{
*Correspondence: zeng1466@126.com; fengwenjun2021@126.com

${ }^{3}$ Department of Orthopaedics, The First Affiliated Hospital of Guangzhou

University of Chinese Medicine, Jichang Road 16\#, District Baiyun, Guangzhou 510405, Guangdong, China

Full list of author information is available at the end of the article
}

knee arthroplasty in the USA is expected to reach 3.48 million [2]. In this context, the increase in the revision rate may follow. Complications such as aseptic loosening, septic loosening, pain, and wear were the most common causes for revisions in TKA [3-5].

As an anatomical structure that restrains valgus and rotatory loads, the medial collateral ligament (MCL) is critical in providing stability after total knee arthroplasty $[6,7]$. According to recent reports, the incidence of intraoperative injury to the MCL is about $0.5 \%$ to $3 \%$ [8-10], which includes transection injuries and avulsions of the femoral and tibial attachment [11-14]. It is 
possible for injury to occur during exposure of the knee and reduction after placement of prosthetic components [15]. In addition, the MCL can be damaged as a result of the direct injury caused by the saw blade and excessive release during surgery [16-18].

Based on the injury types, different treatment options can be adopted, including primary repair [9, 19, 20], augmentation with tendon graft [21-23], fixation with screws and washer construct [19], thicker polyethylene liner [14, 24], and the increase in prosthetic constraint $[8,10]$. At present, a consensus has not yet been reached on the management of MCL injury during TKA, and the impact of the management on patients has remained undetermined. Hence, the purpose of this meta-analysis and systematic review was to review and summarize the available literature regarding MCL injury in TKA and evaluate whether MCL injury impacts clinical outcomes.

\section{Methods}

\section{Search strategy}

The conduction of this meta-analysis and systematic review followed the preferred reporting items for systematic review and meta-analysis (PRISMA) guideline. Subsequently, we searched the following databases: PubMed, Cochrane Library, and EMBASE, until July 1, 2021. To maximize the search results, our search strategy for these three databases followed Medical Subject Headings combination with terms (Additional file 1), but only included articles in English.

\section{Study selection and data extraction}

All titles and abstracts were screened by two researchers (Zijian Yan and Yijin Li) using clearly defined inclusion and exclusion criteria. Only English-language publications on patients who reported MCL injuries during TKA were included for further examination.

According to the PICOS order, the study included in our meta-analysis had to meet all of the following requirements: (1) Population: patients undergoing primary total knee replacement; (2) Intervention: MCL injury group; (3) Comparison intervention: MCL-intact group; (3) At least one of the following indexes was assessed: functional outcomes, Knee Society Score, range of motion, postoperative pain score, complications, revision, and so on.

These studies will be excluded: revision knee replacement, biomechanics, physical and animal studies, conference abstracts, case reports, comments and reports of undefined MCL injuries.

Data extraction of all included studies was performed independently by two authors (Zijian Yan and Yijin Li) according to the Cochrane guidelines. Relevant data extracted included publication information (author, study design, and year) and patient baseline characteristics (gender, body mass index [BMI], age, and type of prosthesis). Injury type (transection or avulsion), outcome data, and management were also extracted.

\section{Quality assessment}

Newcastle-Ottawa Scale (NOS) tool was used to assess methodological quality in any of the included studies [25]. This scale contains eight items, which are divided into three dimensions: selection, comparability, outcome measurement. All studies were independently evaluated by two researchers, and disagreements were resolved through discussion by a third reviewer.

\section{Statistical analysis}

All extracted data analysis and picture production were performed with the Review Manager (version 5.4 for Windows). To evaluate the dichotomous variables in the study (such as postoperative complications), we commonly selected the odds ratio (OR) and the associated 95\% confidence interval $(\mathrm{CI})$ to measure. Given that the incidence is rare, the reported OR can be approximated as RR (relative risk) based on Cornfield's research results [26]. Then, we included studies that provided complete mean and standard deviation. Mean difference (MD) or standard mean difference (SMD) were used to analyze continuous variables such as KSS or KFS. $I^{2}$ and $Q$ tests were used to evaluate the heterogeneity between studies. For heterogeneity testing, when $I^{2} \geq 50 \%$, the random effects model was used to replace the fixed effects model [27]. The forest map was used to display the results of the aggregate effect size analysis of each study, while the Deeks' funnel plot was applied to evaluate the publication bias.

\section{Results}

\section{Study selection}

Following the search strategy described above, a total of 622 relevant papers were initially screened from the three databases. After deleting the duplicate literature, 403 articles remained. By reading the titles and abstracts, 366 studies that did not meet our requirements were removed, leaving 37 articles for further reading in fulltext. Finally, 15 articles were included in the systematic review and 10 articles were included in the meta-analysis after reading the full-text, with reasons for exclusion included review, no available outcome data, surgical technique, and in vitro studies. The complete literature screening process was illustrated as PRISMA flow diagram in Fig. 1. 


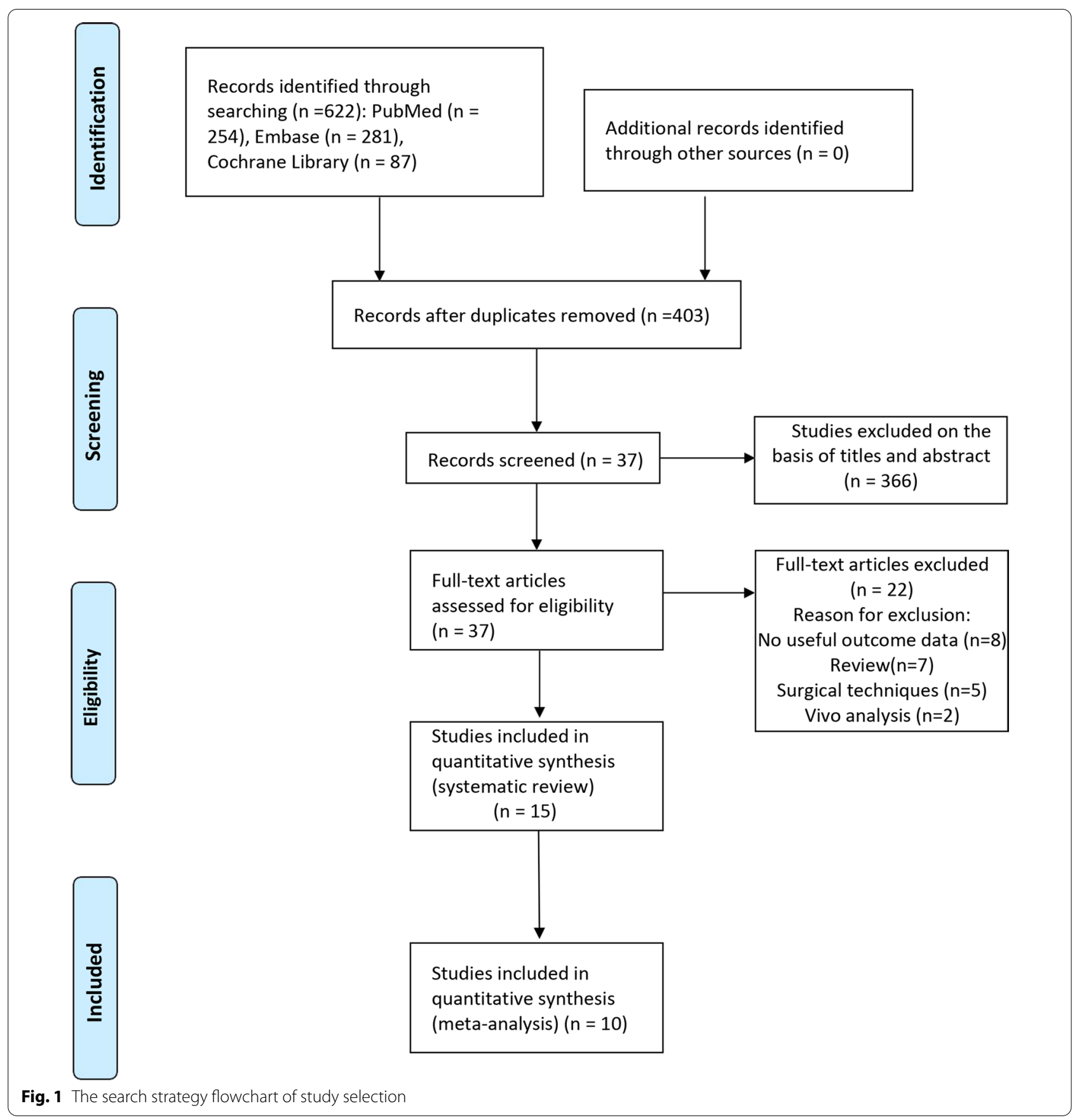

\section{Study characteristics and quality assessment}

Demographics and clinical outcomes of the included studies were summarized in Tables 1 and 2. Among the 15 screened citations, nine were cohort studies $[8,10$, $12,13,20,24,28-30]$, five were retrospective studies [9, $14,19,22,31]$, and one was a case-control study [11]. A total of 376 knees in the medial collateral ligament injury group were studied in comparison with 5025 knees in the control group with intact medial collateral ligaments.
Notably, 166 knees had an intraoperative injury with tear in the mid-substance, while the other 220 knees were avulsion injuries. In terms of clinical outcomes, 11 studies evaluated KSS scores, nine papers compared KFS scores, and six papers had documented ROM in their entirety. Complications and revisions were reported in 7 of the 15 studies, with common reasons such as stiffness, instability, and infection. The quality of 10 studies included in the meta-analysis assessed with the Newcastle-Ottawa 
Table 1 Demographics of the included studies

\begin{tabular}{|c|c|c|c|c|c|c|c|}
\hline Author & Years & Design & Sample size* & Mean age* & $\mathrm{BMI}^{*}$ & Follow-up (Mon)* & Outcome Measures \\
\hline Leopold [9] & 2001 & Retrospective study & $16(2.6 \%)$ & 63 & 32.5 & 45 & Revision, HSS, ROM \\
\hline Koo [24] & 2009 & Cohort study & $15 / 11$ & 63.9 & NR & 24 & Revision, KSS, KFS, ROM \\
\hline Lee [8] & 2011 & Cohort study & $37 / 1613$ & 60 & $N R$ & 44 & Revision, Complications, KSS, KFS \\
\hline Dragosloveanu [14] & 2013 & Retrospective study & $8(1.8 \%)$ & 62.8 & 34 & 12 & Revision, Complications, KSS, KFS \\
\hline Siqueir [10] & 2014 & Cohort study & 23/92 & $66.5 / 69.1$ & $32.7 / 32.8$ & $60.3 / 52$ & Revision, KSS, KFS \\
\hline Shahi [22] & 2014 & Retrospective study & $15(0.43 \%)$ & 64 & 38 & 16 & Revision, KSS, Coronal alignment \\
\hline Cao [13] & 2016 & Cohort study & $11 / 18$ & $64.3 / 63.7$ & $26.75 / 26.37$ & $15.8 / 19.5$ & Revision, KSS, KFS \\
\hline Bohl [19] & 2016 & Retrospective study & $35(1.2 \%)$ & 62 & 34 & 99 & Revision, Complications, HSS, ROM \\
\hline Wang [12] & 2017 & Cohort study & $17 / 1732$ & $63 / 60.7$ & $34.4 / 34.6$ & 51 & Revision, KSS, KFS \\
\hline White [30] & 2018 & Cohort study & $33 / 770$ & $63.6 / 63.6$ & $32.4 / 30.4$ & 31.2 & Revision, Complications, KOOS, VAS \\
\hline $\operatorname{Jin}[20]$ & 2019 & Cohort study & $65 / 65$ & $71.4 / 69.2$ & $26.4 / 26.2$ & $74.1 / 79.8$ & Revision, KSS, WOMAC, ROM \\
\hline Motififard [28] & 2020 & Cohort study & $35 / 618$ & $68 / 66$ & $N R$ & 24 & $\begin{array}{l}\text { Revision, Complications, KSS, KFS, } \\
\text { ROM }\end{array}$ \\
\hline $\mathrm{Ni}[31]$ & 2020 & Retrospective study & 14 & 63.6 & 27.2 & 15.6 & $\begin{array}{l}\text { Revision, HSS, ROM, Coronal align- } \\
\text { ment }\end{array}$ \\
\hline Rajkumar [11] & 2020 & Case-control study & $41 / 82$ & $65.2 / 64.6$ & $33.8 / 33.9$ & 58.4 & $\begin{array}{l}\text { Revision, Complications, KSS, KFS, } \\
\text { ROM }\end{array}$ \\
\hline Sun $[29]$ & 2020 & Cohort study & $11 / 24$ & $64.2 / 63.5$ & $28.33 / 27.47$ & $35.5 / 36$ & Revision, KSS, KFS \\
\hline
\end{tabular}

*The values were given as the number with MCL injury/intact

KSS, Knee Society Score; KFS, Knee Society Functional Score; ROM, range of motion; KOOS, Knee Injury and Osteoarthritis Outcome Score; WOMAC, Western Ontario and McMaster Universities Osteoarthritis Index; VAS, visual analog scale; NR, not reported

scale, ranged from six to eight. Among them, three studies scored 6 points, five studies scored 7 points, and two study scored 8 points (Table 3 ).

\section{Knee Society Score (KSS)}

The KSS score was used in nine studies [10, 12-14, 20, $22,24,28,29]$ and the results in meta-analysis showed significant differences after MCL injury (MD - 1.31, 95\% $\mathrm{CI}-2.64$ to $0.01, P=0.5, I^{2}=0 \%$; Fig. $2 \mathrm{a}$ ). In this metaanalysis, we chose a fixed effect model because the results of the heterogeneity analysis $\left(P=0.05, I^{2}=0 \%\right)$ indicated essentially no heterogeneity. Sensitivity analysis showed no literature that would significantly interfere with the results of the analysis, representing good accuracy and stability of this study. The pooled information was shown in our forest plot (Fig. 2a), and the results revealed that intraoperative injury to the MCL during TKA significantly reduces the postoperative KSS score. To clarify whether publication bias exists, a funnel plot (Fig. 3) was generated to examine. In Fig. 3, the funnel plot appeared symmetrical, which indicated the absence of publication bias.

\section{Knee Function Score (KFS)}

Six studies [10, 12, 13, 24, 28, 29] provided sufficient information and were included in this meta-analysis. Similarly, fixed effects models were used to calculate because no evidence of heterogeneity was found in the study (MD $-1.96,95 \%$ CI -3.55 to $-0.36, P=0.18$, $I^{2}=34 \%$ ). The pooled data showed that MCL injury also significantly decreased KFS scores compared to the control group (Fig. 2b).

\section{Range of motion (ROM)}

ROM was reported in six articles, and three of them met the inclusion criteria [20, 24, 28]. Patients in the MCL injury group had worse mean postoperative ROM compared to those in the MCL-intact group (MD -3.63, 95\% CI -5.97 to $-1.29, P=0.17, I^{2}=43 \%$ ) (Fig. 2 c).

\section{Complications and revision}

After excluding studies without complications and revision, four $[8,10,28,30]$ and three studies $[8,10,28]$ were pooled into the analysis of complications and revisions, respectively. According to Fig. 4, the complication (MD 6.18, 95\% CI 1.71 to $22.32, P=0.05, I^{2}=67 \%$; Fig. 4a) and revision rates (MD 6.31, 95\% CI 3.10 to $12.85, P=0.16$, $I^{2}=41 \%$; Fig. $4 \mathrm{~b}$ ) were six folds higher in the MCL injury group than in the control group. Lee et al. reported seven complications including four instabilities, two aseptic loosening, and one PJI, all of which were eventually revised to TCIII prostheses using cemented femoral and tibial stems [8]. In the study by Motififard et al. [28], five patients treated for MCL insufficiency developed coronal instability, three of whom undergone revision. Furthermore, complications such as instability, screw loosening, 
Table 2 Summary of clinic outcomes for each study

\begin{tabular}{|c|c|c|c|c|c|c|c|c|c|}
\hline \multirow[t]{2}{*}{ Author } & \multirow[t]{2}{*}{ Years } & \multicolumn{2}{|l|}{ MCL injury } & \multirow[t]{2}{*}{ Implant } & \multirow[t]{2}{*}{ Management } & \multirow[t]{2}{*}{ KSS* } & \multirow[t]{2}{*}{ KFS* } & \multirow{2}{*}{$\begin{array}{l}\text { Complications } \\
\text { and revision }\end{array}$} & \multirow[t]{2}{*}{ ROM* } \\
\hline & & Transection & Avulsion & & & & & & \\
\hline Leopold [9] & 2001 & 12 & 4 & $12 \mathrm{CR} / 4 \mathrm{PS}$ & $\begin{array}{l}\text { Suture anchors/ } \\
\text { screw-and- } \\
\text { washer/ suture } \\
\text { repair }\end{array}$ & $N R$ & $N R$ & 1 PJI (1 revision) & G1:108 \\
\hline Koo [24] & 2009 & 0 & 15 & $13 P S / 2 C R$ & $\begin{array}{l}\text { Thicker polyethyl- } \\
\text { ene insert }\end{array}$ & $\begin{array}{l}\mathrm{G} 1: 91 \pm 6.78 / \\
\mathrm{G} 2: 92.20 \pm 3.74\end{array}$ & $\begin{array}{l}G 1: 82.5 \pm 13.57 / \\
G 2: 82.00 \pm 3.59\end{array}$ & 0 & $\begin{array}{l}\mathrm{G} 1: 130 \pm 9 / \\
\mathrm{G} 2: 130 \pm 13\end{array}$ \\
\hline Lee [8] & 2011 & 28 & 9 & 7PS/30 TCIII & $\begin{array}{l}14 \text { ligament } \\
\text { repair /23NR }\end{array}$ & G1:81/G2:91 & $\mathrm{G} 1: 74 / \mathrm{G} 2: 87$ & $\begin{array}{l}4 \text { instability/1 } \\
\text { PJI/2 aseptic loos- } \\
\text { ening (7 Revision) }\end{array}$ & $N R$ \\
\hline $\begin{array}{l}\text { Dragoslove- } \\
\text { anu [14] }\end{array}$ & 2013 & 1 & 7 & 5PS/3 constraint & $\begin{array}{l}7 \text { suture anchor/1 } \\
\text { suture repair }\end{array}$ & $\mathrm{Gl}: 87.7$ & $\mathrm{G} 1: 80$ & $\begin{array}{l}1 \text { instability (1 } \\
\text { revision) }\end{array}$ & $N R$ \\
\hline Siqueir [10] & 2014 & 22 & 1 & $\begin{array}{l}10 \mathrm{PS} / 2 \mathrm{CR} / \\
11 \text { constraint }\end{array}$ & $\begin{array}{l}10 \text { ligament } \\
\text { repair/ } 2 \text { uncon- } \\
\text { strained implant } \\
/ 11 \text { constrained } \\
\text { implant }\end{array}$ & $\begin{array}{l}\mathrm{G} 1: 78.8 \pm 24.4 / \\
\mathrm{G} 2: 86.7 \pm 21\end{array}$ & $\begin{array}{l}\mathrm{G} 1: 67.8 \pm 22.9 / \\
\mathrm{G} 2: 72.2 \pm 25.2\end{array}$ & 0 & NR \\
\hline Shahi [22] & 2014 & 11 & 4 & NR & $\begin{array}{l}15 \text { synthetic } \\
\text { ligament }\end{array}$ & G1:92 & $N R$ & 0 & NR \\
\hline Cao [13] & 2016 & 10 & 1 & $8 P S / 3 C R$ & $\begin{array}{l}11 \text { ligament } \\
\text { repair }\end{array}$ & $\begin{array}{l}G 1: 89.82 \pm 3.76 / \\
G 2: 90.19 \pm 3.39\end{array}$ & $\begin{array}{l}\mathrm{G} 1: 89.54 \pm 3.50 / \\
\mathrm{G} 2: 90 \pm 3.53\end{array}$ & 0 & NR \\
\hline Bohl [19] & 2016 & 24 & 21 & $10 P S / 35 C R$ & $\begin{array}{l}\text { Suture anchors/ } \\
\text { screw-and- } \\
\text { washer/ suture } \\
\text { repair }\end{array}$ & $N R$ & $N R$ & $\begin{array}{l}5 \text { stiffness ( } 1 \text { revi- } \\
\text { sion), } 2 \text { aseptic } \\
\text { loosening ( } 2 \\
\text { revision) }\end{array}$ & G1:110 \\
\hline Wang [12] & 2017 & 12 & 5 & $C R$ & $\begin{array}{l}\text { Ligament recon- } \\
\text { struction }\end{array}$ & $\begin{array}{l}\mathrm{G} 1: 87.7 \pm 6.2 / \\
\mathrm{G} 2: 90.6 \pm 6.9\end{array}$ & $\begin{array}{l}\mathrm{G} 1: 84.7 \pm 5.9 / \\
\mathrm{G} 2: 87.9 \pm 7.6\end{array}$ & 0 & NR \\
\hline White [30] & 2018 & 0 & 33 & $\mathrm{PS} / \mathrm{CR}$ & $\begin{array}{l}\text { Using Bone } \\
\text { Staples }\end{array}$ & NR & NR & $\begin{array}{l}6 \text { subjective } \\
\text { instability/4 mod- } \\
\text { erate to severe } \\
\text { instability }\end{array}$ & $N R$ \\
\hline Jin [20] & 2019 & 0 & 65 & PS & $\begin{array}{l}36 \text { suture } \\
\text { anchor/29 staple }\end{array}$ & $\begin{array}{l}\mathrm{G} 1: 87.3 \pm 7.3 / \\
\mathrm{G} 2: 87.6 \pm 10.1\end{array}$ & $N R$ & 0 & $\begin{array}{l}\mathrm{G} 1: 125.6 \pm 8.9 / \\
\mathrm{G} 2: 128.1 \pm 8.1\end{array}$ \\
\hline Motififard [28] & 2020 & 35 & 0 & PS & $\begin{array}{l}\text { Nonabsorbable } \\
\text { braided suture } \\
\text { repair }\end{array}$ & $\begin{array}{l}\mathrm{G} 1: 81 \pm 17 / \\
\mathrm{G} 2: 86 \pm 15\end{array}$ & $\begin{array}{l}\mathrm{G} 1: 61 \pm 13 / \\
\mathrm{G} 2: 67 \pm 5\end{array}$ & $\begin{array}{l}5 \text { coronal instabil- } \\
\text { ity } \\
\text { (3 Revision) }\end{array}$ & $\begin{array}{l}\mathrm{G} 1: 100 \pm 13 / \\
\mathrm{G} 2: 107 \pm 8\end{array}$ \\
\hline $\mathrm{Ni}[31]$ & 2020 & 0 & 14 & $10 P S / 2 C R / 2 C C K$ & $\begin{array}{l}\text { Screw-and- } \\
\text { washer }\end{array}$ & NR & NR & 0 & $G 1: 103.9 \pm 6.8$ \\
\hline Rajkumar [11] & 2020 & 0 & 41 & PS & $\begin{array}{l}\text { Screw and } \\
\text { washer construct } \\
\text { fixation }\end{array}$ & $\begin{array}{l}\mathrm{G} 1: 85(80 \sim 90) / \\
\mathrm{G} 2: 85(81 \sim 85)\end{array}$ & $\begin{array}{l}\text { G1:90(80-95)/ } \\
\text { G2:90(85-90) }\end{array}$ & $\begin{array}{l}1 \text { screw back- } \\
\text { out/ } \\
1 \text { debridement } \\
\text { for hematom }\end{array}$ & $N R$ \\
\hline Sun [29] & 2020 & 11 & 0 & PS & $\begin{array}{l}\text { Meniscus auto- } \\
\text { graft transfer }\end{array}$ & $\begin{array}{l}\mathrm{G} 1: 95 \pm 4.47 / \\
\mathrm{G} 2: 95.4 \pm 3.88\end{array}$ & $\begin{array}{l}G 1: 91.8 \pm 7.5 / \\
G 2: 90.4 \pm 7.5\end{array}$ & 0 & NR \\
\hline
\end{tabular}

*The values were given as the number with $\mathrm{MCL}$ injury/intact

PS. posterior stabilized; CR, cruciate retaining; NR, not reported; NR, not reported

and postoperative hematoma were reported in the study by Rajkumar and White, which were no clear indications of revision $[11,30]$.

\section{Discussion}

As an uncommon but severe complication, MCL injury in total knee arthroplasty may be significantly underrecognized. Avulsion damage to the MCL, or transection in the middle, can lead to poor postoperative function, instability, loosening, and accelerated polyethylene wear [15]. This was confirmed in our study. This systematic literature review and meta-analysis aimed to report the impact of intraoperative MCL ligament injury on patients undergoing TKA, which may provide recommendations for orthopedic surgeons regarding the treatment of MCL injury. This meta-analysis included 10 studies (9 cohort trials and 1 case-control trial) that analyzed 5313 knees and directly compared the clinical outcomes of the MCL-injured group with those of the MCL-intact control group. Pooled data showed significant differences between the two groups in terms of KSS, KFS, ROM, complications and revision rates. On the basis of the 
Table 3 Quality assessment for the studies included in the meta-analysis (NOS)

\begin{tabular}{lllll}
\hline Study & Selection & Comparability & $\begin{array}{l}\text { Exposure } \\
\text { or } \\
\text { outcome }\end{array}$ & Total score \\
\hline Koo [24] & $\star \star \star$ & $\star \star$ & $\star \star$ & 7 \\
Lee [8] & $\star \star$ & $\star$ & $\star \star \star$ & 6 \\
Siqueir [10] & $\star \star \star$ & $\star \star$ & $\star \star \star$ & 8 \\
Cao [13] & $\star \star \star$ & $\star \star$ & $\star \star$ & 7 \\
Wang [12] & $\star \star \star$ & $\star \star$ & $\star \star$ & 7 \\
White [30] & $\star \star$ & $\star \star$ & $\star \star$ & 6 \\
Jin [20] & $\star \star$ & $\star$ & $\star \star \star$ & 6 \\
Motififard [28] & $\star \star \star$ & $\star \star$ & $\star \star \star$ & 8 \\
Rajkumar [11] & $\star \star$ & $\star \star$ & $\star \star \star$ & 7 \\
Sun [29] & $\star \star \star$ & $\star$ & $\star \star \star$ & 7 \\
\hline
\end{tabular}

$\star \star \star$ indicates strong level of evidence; $\star \star$ indicates moderate level of evidence, $\star$ indicates limited level of evidence

NOS, Newcastle-Ottawa scale available evidence, injury to the MCL during total knee arthroplasty significantly affects surgical outcomes.

The reasons for MCL injury in TKA are complex and multi-factorial. Some of them are avoidable iatrogenic injury by careful preoperative history-taking and physical examination, and the other part depends on the surgeon's intraoperative operation. According to our aggregated data, avulsion injuries account for most injuries (59\%), followed by mid-substance disruptions (41\%) $[8,10-13,20,24,28-30]$. MCL injuries are most common in medial soft tissue release or hyperflexion of the knee during subluxation of the tibia or while trial components were placed in a tight flexion gap [15]. In Rajkumar et al. [11] series, severe varus deformity, knee subluxation and "cup and saucer" shape before surgery were risk factors for MCL avulsion injury. In some cases, due to insufficient protection by retractors, the saw blades that cut the bone can cause direct trauma of

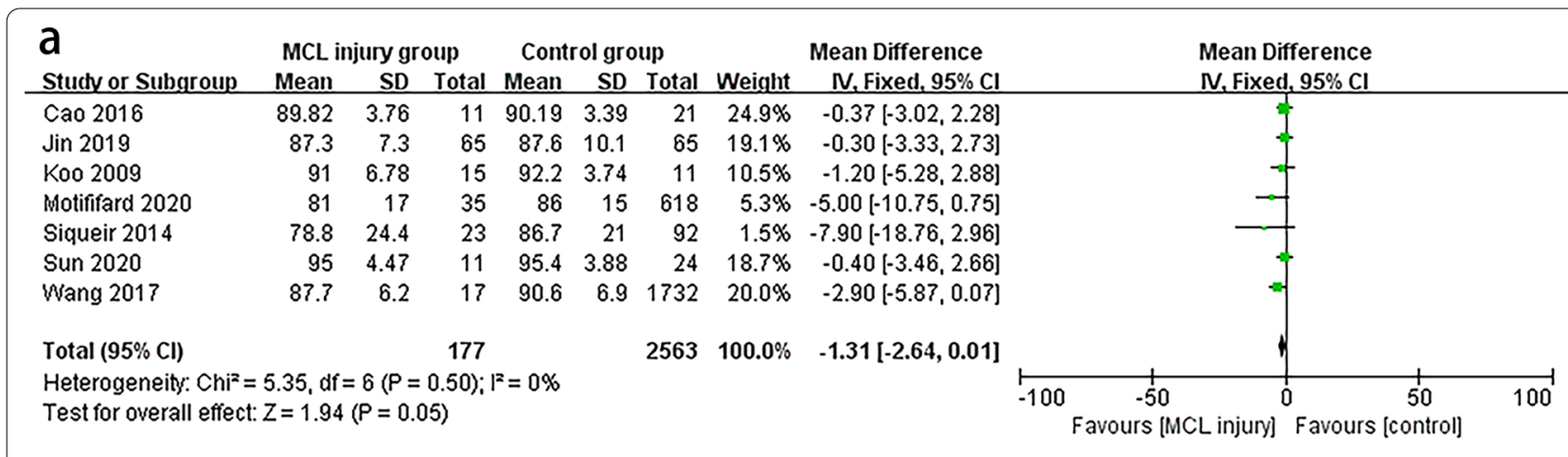

b

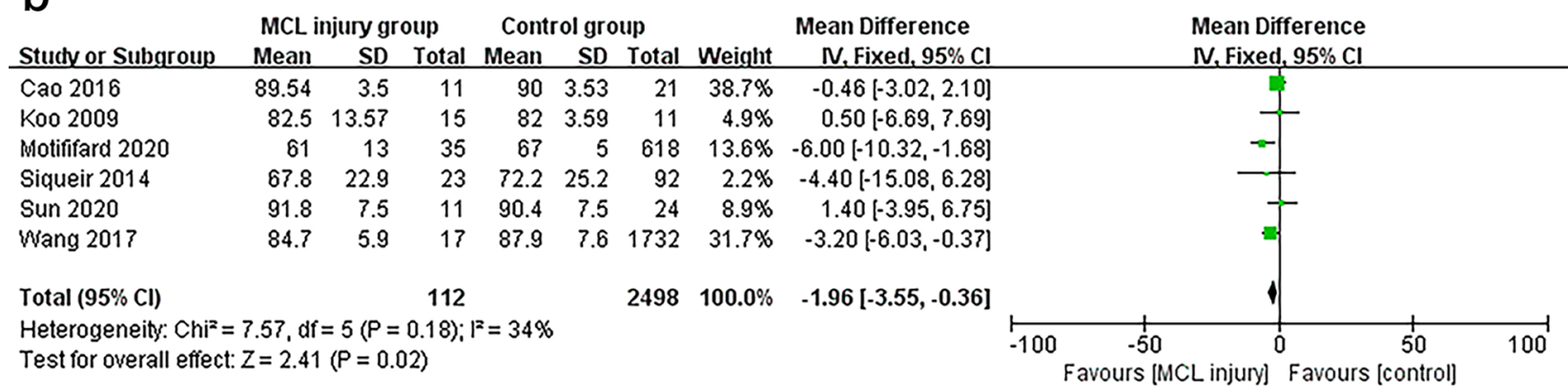

C

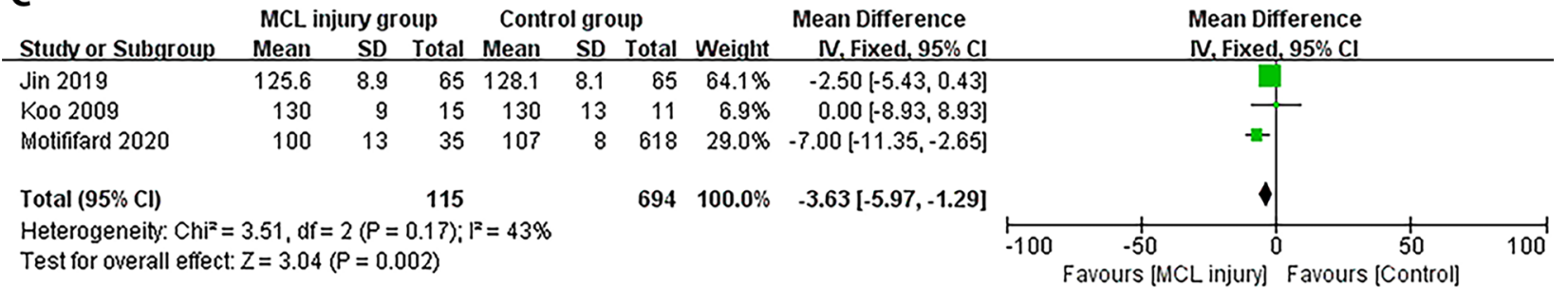

Fig. 2 Forest plots for the KSS (a), KFS (b), and ROM (c). KSS, Knee Society Score; KFS, Knee Society Functional Score; ROM, range of motion; CI, confidence interval 


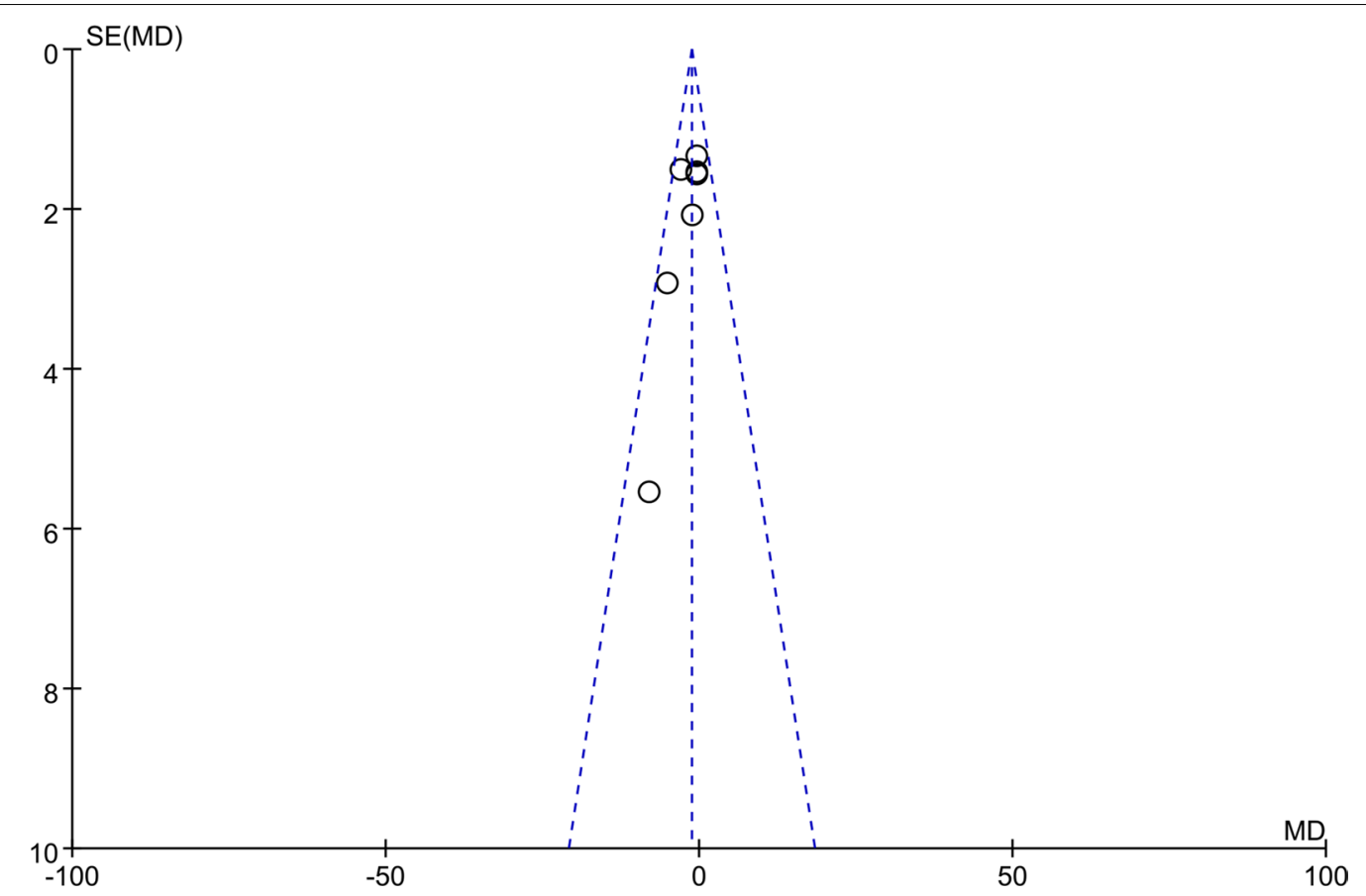

Fig. 3 Funnel plots for reporting the KSS

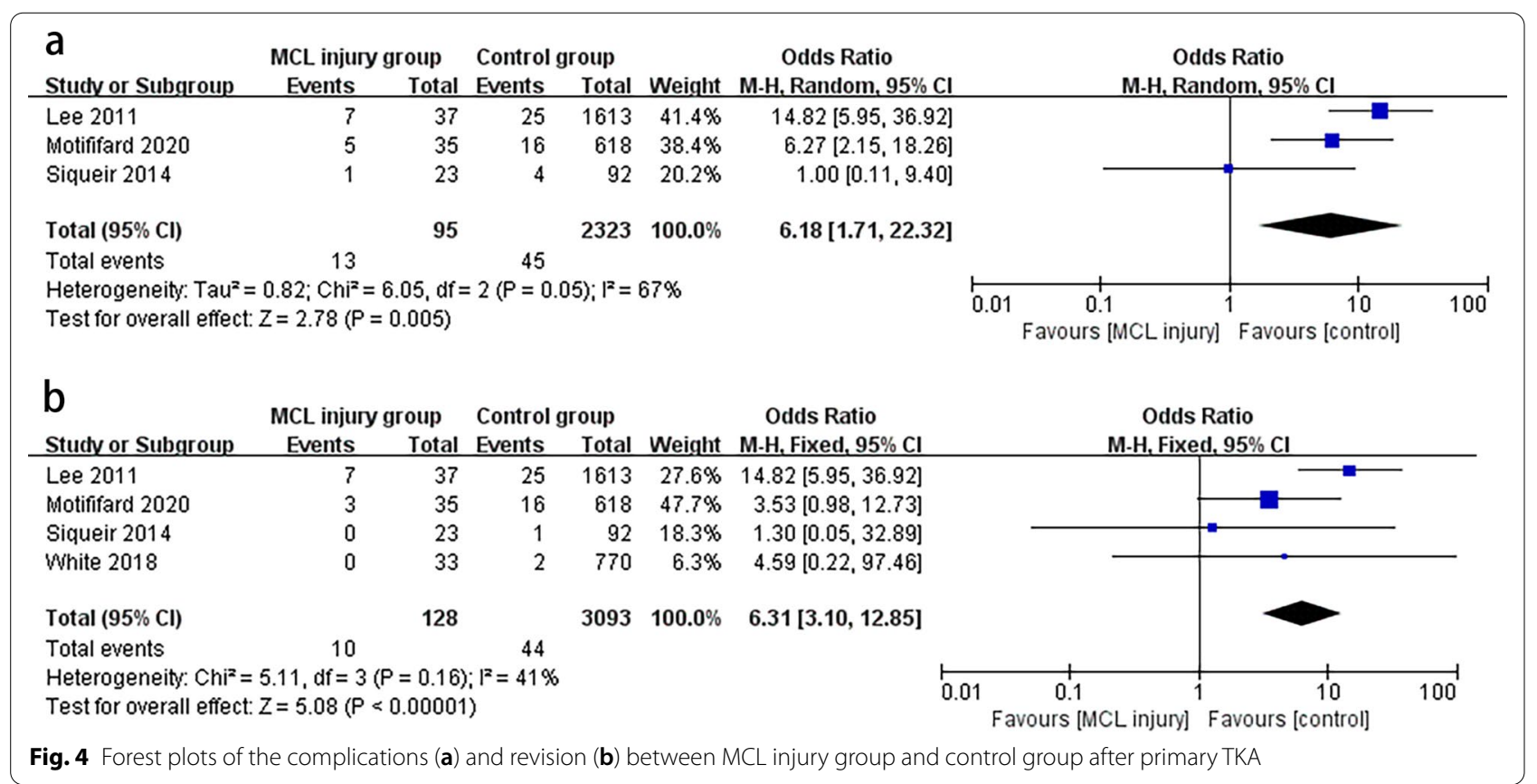

the ligament $[16,32]$. Finally, morbid obesity was also a risk factor for injury, Winiarsky et al. [33] reported 4 cases of intraoperative MCL avulsion injury among 50 morbidly obese patients (8\%), which was significantly higher than that in the control group.
There was no consensus on the optimal management of intraoperative MCL injuries, but the aim was to reconstruct the medial-lateral balance of the knee and maintain coronal stability [34]. Most scholars had addressed this problem by using constrained implants that can 
restore stability to the knee joint after surgery $[8,10,14]$. However, the application of constrained implants may increase the stress on the bone cement and prosthesisbone interface, and the accompanying greater bone loss can make revision difficult [35]. Previous findings had shown that the medial collateral ligament had a good ability to heal after injury [36-38]. Therefore, some scholars adopted for a conservative approach and reported good clinical results [10, 24, 39]. However, it should be applied with caution to patients with high activity requirements [37]. Currently, primary repair of the MCL was usually in the form of suture repair for the disruption of transection and suture anchor or screw-and-washer reattachment for avulsion of the collateral ligament from the femoral or tibial attachments $[9,19,20,30]$. Meanwhile, reconstruction of the MCL has been advocated to treat intraoperative MCL injuries, including the use of autologous quadriceps tendon [21], semitendinosus tendon [12], thin femoral tendon [13], and artificial ligaments [22].

The reasons for the lower scores in patients with MCL injuries in TKA have not been elucidated clearly, but are likely due to instability and stiffness of the knee. Our meta-analysis also showed that the revision rate was higher in the repaired group than in the control group. Of these, only two cases of infection were reported in the study by Lee et al. [8] and Leopold et al. [9]. Therefore, non-infectious complications such as aseptic loosening or instability are regarded as the primary cause for revision after TKA due to its frequency and severity. Traditionally, superficial MCL (sMCL) and deep MCL (dMCL) were important anatomical structures for maintaining knee stability, especially in limiting internal and external rotation [40-42]. In our study, a total of 24 patients reported postoperative instability and aseptic loosening, and 12 patients eventually required revision $[8,14,19$, $28,30]$. Notably, the study by White et al. [30] used bone staples to treat superficial MCL injuries and reported 10 instances of instability (30\%). The incidence was significantly higher than other studies, which we believe was related to the use of an independent questionnaire for assessing stability [30]. Similarly, in the study by Motififard et al. [28], the postoperative instability rate in the MCL repaired group was notable. They attributed this to the use of the pie-crusting technique in the varus deformity. Poorer Postoperative score may result from the stiffness in the repaired group, which may inhibit the range of motion and therefore, patient-reported function. More than $10 \%$ of patients required intervention for stiffness from the report by Bohl et al. [19], and they considered that it may be associated with the use of the hinged knee brace. This finding indicates that when using a hinged knee brace, more emphasis should be placed on the exercise of the range of motion.
This systematic review and meta-analysis are the first to be conducted on MCL injury and clinical outcomes after TKA. However, this study still has its own limitations. Firstly, there is complexity in the spectrum of MCL injury and factors affecting ligament healing, and it has not been reported in detail, so there is heterogeneity among included studies. We tried to contact the authors to obtain the original data, but failed due to time constraints. Therefore, we cannot perform a subgroup analysis to see if the functional outcomes were different with studies reporting avulsions versus mid-substance transections. Secondly, most of the included studies are retrospective cohort studies, which represents that the level of evidence is moderate, and the reliability of the findings needs to be confirmed. Thirdly, MCL injury is a rare complication and the studies we included showed few cases of adverse outcomes and revisions, so longer follow-up and more studies are needed to prove the conclusions of our study.

\section{Conclusion}

Patients receiving TKA with intraoperative MCL injury are at an increased risk of complications and revision in comparison to patients without. Poorer functional outcomes are also associated with MCL injury, although further clarification in future studies is required. It is recommended that surgeons are expected to pay particular attention to these patients, and improve preoperative preparation and surgical techniques to prevent intraoperative MCL injury.

\section{Abbreviations \\ TKA: Total knee arthroplasty; MCL: Medial collateral ligament; ROM: Range of motion; KSS: Knee Society Score; KFS: Knee Function Score.}

\section{Supplementary Information}

The online version contains supplementary material available at https://doi. org/10.1186/s13018-021-02824-5.

Additional file 1. Detailed search strategy of Pubmed.

\section{Acknowledgements}

No acknowledgement

\section{Authors' contributions}

WF and $Y Z$ contributed to the study design. $J L$ and $Y L$ contributed to the drafting of the manuscript. $Y L, Z Y$, and $J L$ conducted the literature search, quality assessment, data collection, and analysis. PD, PY, and JZ solved the cases of doubt. JC, ZH, and XQ reviewed and edited the manuscript. All authors have read and approved the final manuscript.

Funding

This study is supported by National Natural Science Foundation of China (Grant No. 82104882) and Science Fund of Guangdong Traditional Chinese Medicine Bureau (20201091) 


\section{Availability of data and materials}

The authors declare that all the data supporting the findings of this study are available within the article and its supplementary information files.

\section{Declarations}

\section{Ethics approval and consent to participate}

Not applicable.

\section{Consent for publication}

Not applicable.

\section{Competing interests}

The authors declare that they have no competing interests.

\section{Author details}

${ }^{1}$ The First Clinical Medical School, Guangzhou University of Chinese Medicine, Jichang Road 12\#, District Baiyun, Guangzhou, Guangdong, China. ${ }^{2}$ The First Affiliated Hospital of Nanchang University, 17 Yongwai Street, Nanchang 330006, China. ${ }^{3}$ Department of Orthopaedics, The First Affiliated Hospital of Guangzhou University of Chinese Medicine, Jichang Road 16\#, District Baiyun, Guangzhou 510405, Guangdong, China.

Received: 31 August 2021 Accepted: 1 November 2021

Published online: 20 November 2021

\section{References}

1. Weinstein AM, Rome BN, Reichmann WM, Collins JE, Burbine SA, Thornhill TS, Wright J, Katz JN, Losina E. Estimating the burden of total knee replacement in the United States. J Bone Jt Surg Am. 2013;95(5):385-92.

2. Kurtz S, Ong K, Lau E, Mowat F, Halpern M. Projections of primary and revision hip and knee arthroplasty in the United States from 2005 to 2030. J Bone Jt Surg Am. 2007;89(4):780-5.

3. Sadoghi P, Liebensteiner M, Agreiter M, Leithner A, Böhler N, Labek G. Revision surgery after total joint arthroplasty: a complicationbased analysis using worldwide arthroplasty registers. J Arthroplasty. 2013;28(8):1329-32.

4. Belmont PJ Jr, Goodman GP, Waterman BR, Bader JO, Schoenfeld AJ. Thirty-day postoperative complications and mortality following total knee arthroplasty: incidence and risk factors among a national sample of 15,321 patients. J Bone Jt Surg Am. 2014;96(1):20-6.

5. Bozic KJ, Kurtz SM, Lau E, Ong K, Vail TP, Berry DJ. The epidemiology of revision total hip arthroplasty in the United States. J Bone Jt Surg Am. 2009:91(1):128-33.

6. Athwal KK, Willinger L, Shinohara S, Ball S, Williams A, Amis AA. The bone attachments of the medial collateral and posterior oblique ligaments are defined anatomically and radiographically. Knee Surg Sports Traumatol Arthrosc: Off J ESSKA. 2020;28(12):3709-19.

7. Wymenga AB, Kats JJ, Kooloos J, Hillen B. Surgical anatomy of the medial collateral ligament and the posteromedial capsule of the knee. Knee Surg Sports Traumatol Arthrosc: Off J ESSKA. 2006;14(3):229-34.

8. Lee GC, Lotke PA. Management of intraoperative medial collateral ligament injury during TKA. Clin Orthop Relat Res. 2011:469(1):64-8.

9. Leopold SS, McStay C, Klafeta K, Jacobs JJ, Berger RA, Rosenberg AG. Primary repair of intraoperative disruption of the medical collateral ligament during total knee arthroplasty. J Bone Jt Surg Am. 2001;83(1):86-91.

10. Siqueira MB, Haller K, Mulder A, Goldblum AS, Klika AK, Barsoum WK. Outcomes of medial collateral ligament injuries during total knee arthroplasty. J Knee Surg. 2016;29(1):68-73.

11. Rajkumar N, Soundarrajan D, Dhanasekararaja P, Rajasekaran S. Influence of intraoperative medial collateral ligament bony avulsion injury on the outcome of primary total knee arthroplasty. J Arthroplasty. 2021;36(4):1284-94.

12. Wang $X$, Liu H, Cao P, Liu C, Dong Z, Qi J, Wang F. Clinical outcomes of medial collateral ligament injury in total knee arthroplasty. Medicine. 2017:96(30):e7617.
13. Cao JG, Wang L, Zhao HW, Liu J. Semitendinosus and gracilis transfer for treatment of medial collateral ligament injury of total knee arthroplasty. Eur Rev Med Pharmacol Sci. 2016;20(18):3738-42.

14. Dragosloveanu S, Cristea S, Stoica C, Dragosloveanu C. Outcome of iatrogenic collateral ligaments injuries during total knee arthroplasty. Eur J Orthop Surg Traumatol: Orthop Traumatol. 2014;24(8):1499-503.

15. Cheung A, Yan CH, Chan PK, Chiu KY. The medial collateral ligament in primary total knee arthroplasty: anatomy, biomechanics, and injury. J Am Acad Orthop Surg. 2020;28(12):e510-6.

16. Dimitris K, Taylor BC, Steensen RN. Excursion of oscillating saw blades in total knee arthroplasty. J Arthroplasty. 2010;25(1):158-60.

17. He X, Cai H, Zhang K. Pie-crusting technique is effective and safe to release superficial medial collateral ligament for total knee arthroplasty. J Orthop Transl. 2018;13:33-40.

18. Ha CW, Park YB, Lee CH, Awe SI, Park YG. Selective medial release technique using the pie-crusting method for medial tightness during primary total knee arthroplasty. J Arthroplasty. 2016;31(5):1005-10.

19. Bohl DD, Wetters NG, Del Gaizo DJ, Jacobs JJ, Rosenberg AG, Della Valle CJ. Repair of intraoperative injury to the medial collateral ligament during primary total knee arthroplasty. J Bone Jt Surg Am. 2016;98(1):35-9.

20. Jin C, Zhao JY, Santoso A, Song EK, Chan CK, Jin QH, Ko JW, Seon JK. Primary repair for injury of medial collateral ligament during total-knee arthroplasty. Medicine. 2019;98(39):e17134.

21. Jung KA, Lee SC, Hwang SH, Jung SH. Quadriceps tendon free graft augmentation for a midsubstance tear of the medial collateral ligament during total knee arthroplasty. Knee. 2009;16(6):479-83.

22. Shahi A, Tan TL, Tarabichi S, Maher A, Della Valle C, Saleh UH. Primary repair of iatrogenic medial collateral ligament injury during TKA: a modified technique. J Arthroplasty. 2015;30(5):854-7.

23. Kitamura N, Ogawa M, Kondo E, Kitayama S, Tohyama H, Yasuda K. A novel medial collateral ligament reconstruction procedure using semitendinosus tendon autograft in patients with multiligamentous knee injuries: clinical outcomes. Am J Sports Med. 2013;41(6):1274-81.

24. $\mathrm{Koo} \mathrm{MH}$, Choi $\mathrm{CH}$. Conservative treatment for the intraoperative detachment of medial collateral ligament from the tibial attachment site during primary total knee arthroplasty. J Arthroplasty. 2009;24(8):1249-53.

25. Stang A. Critical evaluation of the Newcastle-Ottawa scale for the assessment of the quality of nonrandomized studies in meta-analyses. Eur J Epidemiol. 2010;25(9):603-5.

26. Cornfield J. A method of estimating comparative rates from clinical data; applications to cancer of the lung, breast, and cervix. J Natl Cancer Inst. 1951;11(6):1269-75.

27. Higgins JP, Thompson SG, Deeks JJ, Altman DG. Measuring inconsistency in meta-analyses. BMJ (Clin Res Ed). 2003;327(7414):557-60.

28. Motififard M, Sheikhbahaei E, Piri Ardakani M, Cheraghsahar H, Shahzamani A. Intraoperative repair for iatrogenic MCL tear due to medial piecrusting in TKA yields satisfactory mid-term outcomes. Knee Surg Sports Traumatol Arthrosc: Off J ESSKA. 2020;29(10):3246-53.

29. Sun C, Rong W, Du R, Wu S, Liu P, Zhang W, Cai X. Meniscus graft augmentation for a midsubstance tear of the medial collateral ligament during total knee arthroplasty. J Knee Surg. 2020. https://doi.org/10.1055/s-00401715115.

30. White KT, Fleischman A, Ackerman CT, Chen AF, Rothman RH. Managing superficial distal medial collateral ligament insufficiency in primary total knee arthroplasty using bone staples. J Knee Surg. 2019;32(9):900-5.

31. Ni M, Sun JY, Fu J, Du YQ, Shen JM, Yang XX, Zhou YG, Zhang GQ, Chen JY. Management of medial collateral ligament insufficiency during total knee arthroplasty with a screw and rectangular spiked washer: a case series of 14 patients. Orthop Surg. 2020;12(6):1784-91.

32. Lachiewicz PF, Soileau ES. Ten-year survival and clinical results of constrained components in primary total knee arthroplasty. J Arthroplasty. 2006;21(6):803-8.

33. Winiarsky $R$, Barth $P$, Lotke P. Total knee arthroplasty in morbidly obese patients. J Bone Jt Surg Am. 1998;80(12):1770-4.

34. Heller KD. Intraoperative damage to the medial collateral ligament $(\mathrm{MCL})$ - what is to be done? Zeitschrift fur Orthopadie und Unfallchirurgie. 2013;151(6):580-4.

35. Vasso M, Beaufils P, Schiavone Panni A. Constraint choice in revision knee arthroplasty. Int Orthop. 2013;37(7):1279-84.

36. Georgiev GP, Kotov G, Iliev A, Kinov P, Angelova J, Landzhov B. Comparison between operative and non-operative treatment of the medial 
collateral ligament: histological and ultrastructural findings during early healing in the epiligament tissue in a rat knee model. Cells Tissues Organs. 2018;206(3):165-82.

37. Halinen J, Lindahl J, Hirvensalo E, Santavirta S. Operative and nonoperative treatments of medial collateral ligament rupture with early anterior cruciate ligament reconstruction: a prospective randomized study. Am J Sports Med. 2006:34(7):1134-40.

38. Wright RW, Parikh M, Allen T, Brodt MD, Silva MJ, Botney MD. Effect of hemorrhage on medial collateral ligament healing in a mouse model. Am J Sports Med. 2003;31(5):660-6.

39. Choi YJ, Lee KW, Seo DK, Lee SK, Kim SB, Lee HI. Conservative management after intraoperative over-release of the medial collateral ligament from its tibial insertion site in patients undergoing total knee arthroplasty. J Knee Surg. 2018;31(8):786-91.
40. Gardiner JC Weiss JA, Rosenberg TD. Strain in the human medial collateral ligament during valgus loading of the knee. Clin Orthop Relat Res. 2001;391:266-74

41. lizawa N, Mori A, Majima T, Kawaji H, Matsui S, Takai S. Influence of the medial knee structures on valgus and rotatory stability in total knee arthroplasty. J Arthroplasty. 2016;31(3):688-93.

42. Robinson JR, Bull AM, Thomas RR, Amis AA. The role of the medial collateral ligament and posteromedial capsule in controlling knee laxity. Am J Sports Med. 2006;34(11):1815-23.

\section{Publisher's Note}

Springer Nature remains neutral with regard to jurisdictional claims in published maps and institutional affiliations.
Ready to submit your research? Choose BMC and benefit from:

- fast, convenient online submission

- thorough peer review by experienced researchers in your field

- rapid publication on acceptance

- support for research data, including large and complex data types

- gold Open Access which fosters wider collaboration and increased citations

- maximum visibility for your research: over $100 \mathrm{M}$ website views per year

At BMC, research is always in progress.

Learn more biomedcentral.com/submissions 